\title{
VALORES ORIENTADORES PARA AVALIAÇÃO DA CONTAMINAÇÃO EM SOLO E ÁGUA - estudo de caso
}

\author{
ORIENTING VALUES OF QUALITY FOR EVALUATION OF THE \\ CONTAMINATION IN GROUND AND WATER - case study
}

\author{
FERREIRA, Jessé Gonçalves ${ }^{1}$; OLIVEIRA, Marcio Joaquim Estefano de ${ }^{2}$
}

1. Mestrando. Programa de Pós-Graduação em Ciências Ambientais - UNITAU

2. Dr. Engenharia Civil, UNITAU Professor do Programa de Pós-Graduação em Ciências Ambientais.

Recebido: 04/08/06 Aceite: 04/09/06

\section{RESUMO}

A utilização de valores orientadores de qualidade de solo e águas subterrâneas como metodologia para avaliação de áreas degrada é muito discutida. A aplicação deste método quando feita de forma simplesmente comparativa com valores determinados para outras regiões e até mesmo países podem resultar em avaliações extremamente equivocadas. Este trabalho teve como objetivo avaliar a metodologia de valores orientadores aplicados a uma área sob influência marinha próxima a um Aterro de Resíduos na região Sul do Brasil e comparando-a com os valores de Intervenção definidos para o Estado de São Paulo. Utilizando-se o software ProUCL para análise estatística determinou-se as concentrações naturais das substâncias naquela região específica. Devido à influência marinha na região as concentrações naturais já se apresentam maiores que as definidas como "Valor de Intervenção" para o Estado de São Paulo. Desta forma pode-se concluir que a utilização de valores orientadores é para avaliação de áreas contaminadas é muito útil, trazendo resultados rápidos de forma simples, no entanto sempre deverão ser utilizados de forma criteriosa para as características de cada região.

Palavras-chave: Área contaminada; Valores orientados; Contaminação do solo.

\section{ABSTRACT}

The use of orienting values of quality of soil and underground waters as methodology for evaluation of areas degraded is much argued. The application of this method when made of simply comparative form with values determined for other regions or even countries can result in extremely mistaken evaluations. The objective of this research was to evaluate the methodology of orienting values applied to an area under sea influence next to a landfill in the South region of Brazil and comparing it with the defined values of Intervention for the State of São Paulo. Using ProUCL software for statistics analysis was determined the natural concentrations of substances in that specific region. Due to sea influence in the region the natural concentrations already present were greater that the defined ones as "Value of Intervention" for the State of São Paulo. Based in this it can be concluded that the use of orienting values for evaluation of contaminated areas is very useful, bringing results in a simple and fast way, however will always have to be used in careful way for the characteristics of each region.

Key words: Contaminated areas; Orienting values; Contamination of soil. 


\section{INTRODUÇÃO}

A utilização de valores orientadores de qualidade de solo e águas subterrâneas como referência para a avaliação de áreas degradadas vem sendo empregada há vários anos no Brasil, principalmente no Estado de São Paulo.

Os valores de referência mais utilizados foram a Lista Holandesa de Valores Orientadores e os Valores SSL (Soil Screen Levels) da Agência Ambiental Americana EPA. No entanto estes valores correspondem a características ambientais de cada país.

Sua utilização como parâmetro de qualidade para solos tropicais, como é o caso do Brasil, gerou muitas discussões, o que levou a Companhia Estadual de Saneamento Ambiental do Estado de São Paulo - CETESB a criar seus próprios valores de referência para o Estado de São Paulo, recentemente aprovados pela Decisão de Diretoria No 195-2005-E, de 23 de novembro de 2005 da CETESB.

Como os valores de referência estrangeiros empregados no Brasil, os valores orientadores definidos para o Estado de São Paulo representam as diversas características ambientais existentes no Estado.

Outros órgãos de proteção ao meio ambiente de outros estados brasileiros, por não possuírem seus próprios valores orientadores definidos, passaram a utilizar os valores definidos pela CETESB. Como ocorrido com os valores estrangeiros utilizados, estes valores não caracterizam outras regiões do país, que conseqüentemente precisam de parâmetros regionais adequados.

Como conseqüência, um aterro de resíduos localizado na região Sul do Brasil foi obrigado pelo órgão ambiental de seu Estado a construir poços de monitoramento de aqüífero freático para verificar possível contaminação da área de influência do empreendimento.

As primeiras análises de água realizadas constataram que o aqüífero sob influência do aterro estava contaminado com concentrações de metais pesados superiores ao Valor de Intervenção definido pela CETESB.

No entanto, no início dos estudos não foi considerada a influência marinha na área, evidente pela presença de camada de argila marinha encontrada durante as sondagens mecânicas, além dos vestígios de animais marinhos como "conchinhas", por exemplo.

Assim, admitiu-se que a área em estudo não se enquadrava nos padrões préestabelecidos pela CETESB, e que seriam necessários adquirir os valores de referência de qualidade específicos para a região em estudo.

A área em estudo possibilitou a coleta de amostras que representam uma situação de "Background", ou seja, amostras que representem a qualidade natural do solo sem qualquer possibilidade de intervenção antrópica significativa.

Através dos valores de referência estabelecidos especificamente para a área sob referência do aterro, foi possível verificar que as características ambientais daquele local específico já possuíam naturalmente valores superiores aos estabelecidos pela CETESB. 


\section{MATERIAL E MÉTODOS}

Os trabalhos foram realizados de acordo com o Manual de Gerenciamento de Áreas Degradadas da Companhia de Tecnologia e Saneamento Ambiental do Estado de São Paulo - CETESB (2001).

Os dados analíticos fornecidos correspondem as seguintes substâncias: Alumínio, Bário, Cádmio, Chumbo, Cloreto, Cobre, Condutividade, Cromo, Ferro, Manganês, Mercúrio, Níquel, Prata, Selênio, Sódio, Sulfato, Zinco.

A partir disso, passou-se a aquisição de dados já levantados pelo proprietário sobre a área em estudo, tais como: Mapa potenciométrico, sondagens de solo e geofísica, os quais forneceram subsídios para a locação dos poços de montante e jusante da área em estudo.

A existência de mata nativa, sem qualquer vestígio de intervenção humana passível de causar qualquer tipo de degradação do solo e águas subterrâneas, a montante da área de influência do aterro e sua conservação possibilitaram a instalação de poços de montante que caracterizassem a qualidade do solo e águas subterrâneas naturais da região sob influência do empreendimento, ou seja, as análises do solo retiradas destes poços irão servir como os valores de referência de qualidade para a região sob influência do aterro de resíduos.

A amostragem dos poços foi realizada de acordo com a norma NBR 13.895 da ABNT, utilizando-se bailers descartáveis.

Os poços foram limpos e esgotados de acordo com a quantidade de água constante em cada um. Para a coleta das amostras de água utilizou-se um bailer de um litro para cada poço.

As amostras eram retiradas e armazenadas em frascos adequados para conservação, de acordo com cada parâmetro a ser analisado. Os frascos eram então tampados e guardados em caixas de isopor para envio ao laboratório.

As amostras coletadas foram analisadas por laboratório terceirizado.

Após análise das amostras de água, determinou-se o valor representativo dos "contaminantes" através de análises estatísticas. Utilizou-se o critério do Limite Superior de Confiança (UCL - upper confidence limit) com 95\% de probabilidade. $O$ método para calcular o UCL depende da distribuição estatística dos dados (distribuição normal, distribuição gama, distribuição lognormal etc.).

O intervalo de confiança de $95 \%$ significa que existe apenas $5 \%$ de probabilidade que a média da área inteira se encontra fora dos limites definidos pela faixa do intervalo de confiança de $95 \%$. O intervalo de confiança depende do número das amostras analisadas.

Para a análise estatística utilizou-se um software específico, o mais utilizado para este tipo de análise é o ProUCL Versão 3.0 da United States Environmental Protection Agency (EPA), que neste caso foi utilizado com a finalidade específica de estimar os valores "background" de concentração de contaminantes.

Para inserção dos dados no software foi necessário montar uma tabela em Excel ${ }^{\circledR}$ com todos as substâncias e resultados encontrados para posteriormente exportar para o ProUCL.

Após análise dos dados pelo software é apresentada uma nova planilha para cada parâmetro com os resultados. 
Utilizando-se do software, foram realizados todos os cálculos estatísticos de acordo com os 15 métodos para cada parâmetro e também determinado qual o melhor método e valor a ser utilizado como referência.

\section{RESULTADOS E DISCUÇÕES}

Após tratamento estatístico dos dados coletados, montou-se a tabela 1 para comparação dos valores "Background" (referente aos poços de montante) e os valores encontrados na área sob influência do aterro de resíduos.

Tabela 1 - RESULTADOS DAS ANÁLISES ESTATÍSTICAS PARA CADA PARÂMETRO.

\begin{tabular}{|l|c|l|c|c|c|}
\hline $\begin{array}{c}\text { Parâmetro } \\
\text { s }\end{array}$ & LQ & & Montante & Jusante & $\begin{array}{c}\text { CETESB } \\
\text { (Valores de } \\
\text { Intervenção) }\end{array}$ \\
\hline Alumínio & 0,05 & $\mathrm{mg} / \mathrm{L}$ & 0,3 & 0,1 & 0,2 \\
\hline Bário & 0,05 & $\mathrm{mg} / \mathrm{L}$ & 0,1 & 0,1 & 0,7 \\
\hline Chumbo & 0,01 & $\mathrm{mg} / \mathrm{L}$ & 0,07 & 0,02 & 0,01 \\
\hline Cloreto & 1,0 & $\mathrm{mg} / \mathrm{L}$ & 7,6 & 163,4 & $\mathrm{NC}$ \\
\hline Cobre & 0,05 & $\mathrm{mg} / \mathrm{L}$ & 0 & 0 & 2 \\
\hline $\begin{array}{l}\text { Condutividad } \\
\text { e }\end{array}$ & 0,2 & $\mu \mathrm{\mu S} / \mathrm{c}$ & 621 & 1371 & $\mathrm{NC}$ \\
\hline Ferro & 0,10 & $\mathrm{mg} / \mathrm{L}$ & 4,1 & 2,7 & 0,3 \\
\hline Manganês & 0,05 & $\mathrm{mg} / \mathrm{L}$ & 0,2 & 0,5 & 0,1 \\
\hline Sódio & 0,5 & $\mathrm{mg} / \mathrm{L}$ & 223 & 68 & $\mathrm{NC}$ \\
\hline Sulfato & 5 & $\mathrm{mg} / \mathrm{L}$ & 24 & 13 & $\mathrm{NC}$ \\
\hline Zinco & 0,05 & $\mathrm{mg} / \mathrm{L}$ & 0,09 & 0 & 5 \\
\hline
\end{tabular}

Conforme apresentado na TABELA 1, verifica-se nos poços de jusante que os valores referentes aos parâmetros Chumbo, Ferro e Manganês estão acima do valor de Referência de Intervenção da CETESB, ou seja, a área deveria sofrer uma intervenção para remediação da contaminação por estes metais pesados.

No entanto, comparando-se com os valores encontrados para os poços de montante, verifica-se que estes são maiores que os de jusante para os parâmetros Chumbo e Ferro. Quanto a Manganês, o valor apresenta-se menor em relação ao valor de jusante, mas ainda superior à referência da CETESB.

Para o parâmetro Alumínio, tem-se uma inversão, pois o valor de jusante ficou abaixo do valor estabelecido pela CETESB, enquanto o valor de montante ("Background") ficou acima.

Os parâmetros Cloreto e Condutividade não são referenciados pela CETESB, e apresentaram grandes diferenças, os valores de jusante são bem maiores que os de montante. Diferentemente, os parâmetros Sódio e Sulfato, que também não são referenciados, são bem maiores nos poços de montante do que nos de jusante, o que significa que a grande quantidade de Cloreto nos poços de Jusante está elevando a Condutividade.

Todos os outros parâmetros com valor zero representam valores abaixo do limite de detecção do equipamento de análise, e neste caso, abaixo dos limites estabelecidos pela CETESB. 


\section{CONCLUSÃO}

A partir dos dados analisados conclui-se que:

A utilização do método de valores orientadores deve ser utilizado antes de avaliações mais detalhadas e caras.

O método é simples, rápido e prático, no entanto deve ser aplicado por pessoa capacitada, em condição de definir corretamente a localização dos poços e, principalmente, saber identificar a importância de cada parâmetro e sua concentração.

No caso apresentado, a simples utilização do método serviu para demonstrar que as concentrações das substâncias eram às naturalmente existentes e não influência do aterro. Esta afirmação é corroborada pela caracterização geológica local.

\section{REFERÊNCIAS BIBLIOGRÁFICAS}

COMPANHIA DE TECNOLOGIA DE SANEAMENTO AMBIENTAL. Manual de gerenciamento de áreas contaminadas. São Paulo, 1999.

. Manual de gerenciamento de áreas contaminadas. São Paulo :

CETESB, 2001. 2.ed. 389p.

Relatório de estabelecimento de valores orientadores para solos e água subterrânea no Estado de São Paulo. São Paulo: CETESB, 2001. 247p.

United States Environmental Agency - EPA. ProUCL Version 3.0 User Guide. April, 2004.

ALLOWAY, B. J. Heavy metals in soils. New York: Wiley, 1990. 339p.

ANJOS, J.A.S.A. dos. Estratégias para remediação de um sítio contaminado por metais pesados - estudo de caso. São Paulo, 1998. 157p. Dissertação (Mestrado) - Escola Politécnica, Universidade de São Paulo.

BORBA, R.P. Arsênio em ambiente superficial: Processos geoquímicos naturais e antropogênicos em uma área de mineração aurífera. Campinas, 2002. 115p. Tese (Doutorado) - Instituto de Geociências, Universidade de Campinas.

CAMARGO, O. A. de; ALLEONI, L. R. F.; CASAGRANDE, J. C. Reações dos micronutrients e elementos tóxicos. In: FERREIRA, M. E.; CRUZ, M. C. P. da; van RAIJ, B.; ABREU, C. ${ }^{a}$ de (Ed.). Micronutrientes e elementos tóxicos na agricultura. Jaboticabal: CNPq/FAPESP/POTAFOS, 2001. cap. 5, p.89-124.

CROZERA, E. H. Identificação das áreas contaminadas no município de Ribeirão Pires - São Paulo. São Paulo, 2001. 189p, Tese (Doutorado) - Instituto de Geociência - Universidade de São Paulo. 
CUNHA, R.C.A. Avaliação de risco em áreas contaminadas por fontes industriais desativadas - estudo de caso. São Paulo, 1997. 152p, Tese (Doutorado) - Instituto de Geociências, Universidade de São Paulo.

HASSUDA, S. Critérios para a gestão de áreas suspeitas ou contaminadas por resíduos sólidos - estudos de caso na região metropolitana de São Paulo. São Paulo, 1997. 142p.

POMPÉIA, S.L. Procedimentos técnicos para recuperação de áreas degradadas por poluição. In: SIMPÓSIO SUL AMERICANO, SIMPÓSIO DE RECUPERAÇÃO DE ÁREAS DEGRADADAS. Foz do Iguaçu, 1994. Anais. Curitiba, FUPEP, 1994. v. 1, p. 63-74.

ROEHRIG, J.; SINGER, E.M. Técnicas de remediação de sítios contaminados. Revista Saneamento Ambiental. São Paulo, 1996. v.7, n. 37, p.19-27.

SCHROEDER, H. A. Essential trace metals in man: copper. Journal of Chronic Diseases, v.19, p.1007-1034. 1996.

SíGOLO, J.B. Resíduos de origem industrial, os metais pesados e o solo: estudo de casos. In: WORKSHOP SOBRE ÁREAS CONTAMINADAS. São Paulo, 1997.

Resumos Expandidos. CETESB/GTZ/USP, p.25-28.

SILVA, A.L.B. Caracterização ambiental e estudo do comportamento do chumbo, zinco e boro em áreas degradadas por indústrias cerâmicas, região dos lagos de Santa Gertrudes, SP. São Paulo, 2001. 157p.

SILVA, F.A.N. Avaliação ambiental preliminar de antigas áreas de disposição de resíduos sólidos urbanos do município de São Paulo. São Paulo. 2001. 104p.

TOSO JUNIOR, E. Avaliação da contaminação e do risco associado em áreas de indústria e suas adjacências, em Cotia-SP. São Paulo, 2001. 130p. 